\title{
Adult attention-deficit Hyperactivity disorder: From clinical reality toward conceptual clarity
}

\begin{abstract}
A B S T R A C T
Jyoti Prakash,

K. Chatterjee, S. Guha ${ }^{1}$,

K. Srivastava ${ }^{2}$,

\section{S. Chauhan}

Departments of Psychiatry and ${ }^{2}$ Clinical Psychologist, Armed Forces Medical College, Pune, Maharashtra, India, ${ }^{1}$ Private Consultant Psychiatrist,

There is ambiguity about the clinical picture and concept of attention-deficit hyperactivity disorder (ADHD) in adults. Relevant literature was extracted from various search engines, analyzed, and interpreted. Available literature suggests a significant prevalence of ADHD in the adult population affecting the quality of socio-occupational functioning. Inattentiveness was more commonly present than hyperactivity-impulsivity. Frequent comorbidities with other psychiatric disorders like anxiety disorders and substance use disorders were noted. Pharmacological management and psychotherapy have been found effective in its management. ADHD is a disorder across the lifespan and fairly prevalent among adults. Greater awareness and more research are required for a better understanding of Adult ADHD and its effective management.
\end{abstract} Sr Lecturer UQ School of Medicine and Griffith University School of Medicine, Australia

\section{Address for correspondence:}

Prof. Jyoti Prakash,

Department of Psychiatry,

Armed Forces Medical

College, Pune - 441040 ,

Maharashtra, India.

E-mail: drjyotiprakashpsy@

yahoo.com

Received: 09 January 2021

Revised: 25 March 2021

Accepted: 29 March 2021

Published: 10 June 2021
$\mathrm{E}$ tiological and clinic-phenomenological paradigms in psychiatry have been changing, with newer scientific revelations and clinical consensus. The paradigm shift in attention-deficit hyperactivity disorder (ADHD) appears to have been swifter than the others. From a relatively uncommon hyperactivity reaction and a disorder of children, it has come a long way to now be seen as a widely prevalent, significantly comorbid, highly heritable disorder across the entire lifespan. Here, we follow its evolution as a clinical entity, review concerns which led researchers to a wider exploration of the construct, and the evolving treatment guidelines.

\begin{tabular}{|c|c|}
\hline \multicolumn{2}{|c|}{ Access this article online } \\
\hline Quick Response Code: & Website: www.industrialpsychiatry.org \\
\hline & DOI: 10.4103/ipj.ipj_7_21 \\
\hline
\end{tabular}

\section{REVISITING ATTENTION-DEFICIT HYPERACTIVITY DISORDER: EVOLUTION OF THE CONSTRUCT}

Early in the $20^{\text {th }}$ century, ADHD was described as an abnormal defect in moral control of children. ${ }^{[1]}$ Subsequent research characterized ADHD as stemming from minimal brain dysfunction, leading to qualitative changes in the behavior of children. ${ }^{[2]}$ DSM II in 1968, gave it nosological legitimacy as "Hyperactivity reaction of childhood." [3] As late as DSM IV, ADHD was described as a disorder diagnosed in infancy, childhood, or adolescence. ${ }^{[1]}$ Subsequent research led DSM V describing ADHD as a

This is an open access journal, and articles are distributed under the terms of the Creative Commons Attribution-NonCommercial-ShareAlike 4.0 License, which allows others to remix, tweak, and build upon the work non-commercially, as long as appropriate credit is given and the new creations are licensed under the identical terms.

For reprints contact: WKHLRPMedknow_reprints@wolterskluwer.com

How to cite this article: Prakash J, Chatterjee K, Guha S, Srivastava K, Chauhan VS. Adult attention-deficit Hyperactivity disorder: From clinical reality toward conceptual clarity. Ind Psychiatry J 2021;30:23-8. 
disorder across the lifespan ${ }^{[4]}$ From there arose the term Adult ADHD, which clinicians are still uncomfortable or unfamiliar with. Till DSM IV-TR, ADHD was recognized as a triad of symptom-clusters of inattention, hyperactivity, and impulsivity, with onset before 7 years of age and causing impairment in social, academic, and occupation functioning. The subtypes were predominantly inattentive, predominantly hyperactive-impulsive, and combined type. ${ }^{[5]}$

\section{DISQUIET WITH THE EXISTING PARADIGM}

Clinicians and researchers noticed that many patients with ADHD carried symptoms over into adulthood, which affected their socio-occupational functioning adversely. Cherkasova et al. described that $60 \%$ of the children with ADHD continued to be symptomatic into adulthood. ${ }^{[6]}$ Researchers found the prevalence of ADHD in adults to be $4.4 \%-5.2 \%$ in the age group of $18-44$ years and $2.8 \%-3.5 \%$ in older adults. ${ }^{[7-10]}$ Das et al. found the prevalence of Adult ADHD to be $2.2 \%$ in the age group of $68-74$ years in comparison to $6.2 \%$ in the age group of $48 \%-52 \% \cdot{ }^{[11]}$ Kessler reported that $45.7 \%$ of children who had ADHD continued to meet the criteria in their adulthood, with $94.9 \%$ of them having the inattention symptom cluster and $34.6 \%$ having the hyperactivity-impulsivity symptom cluster. ${ }^{[12]}$ Decadal trend in a cohort study reported that the prevalence of Adult ADHD in the general population has risen from $0.43 \%$ in 2007 to $0.96 \%$ in 2016 , and incidence rose from 9.43 per 100,000 person-year in 2007 to 13.49 per 100,000 person-year. ${ }^{[13]}$ A ten-country study of ADHD among adult population showed the mean prevalence of Adult ADHD to be 3.5\%, ranging from $0.9 \%$ in Lebanon to $6.3 \%$ in France. ${ }^{[14]}$

Causes of concern:

1. Increasing prevalence: Adult ADHD appears to be fairly prevalent in the general population $(2.5 \%-5 \%)$ and is progressively increasing over the years ${ }^{[8,10,15,16]}$

2. Underdiagnosed entity: Being a poorly understood and hardly explored by clinicians; many individuals with adult ADHD remain undiagnosed and continue to experience suffering. Studies have indicated that $<20 \%$ of ADHD in adults is diagnosed or treated. ${ }^{[10,17,18]}$ About $17 \%-22 \%$ of adults reporting to psychiatric services reporting for other mental conditions have been found to have $\mathrm{ADHD}^{[19-21]}$

3. High comorbidity: ADHD in adults is significantly comorbid with other psychiatric and medical conditions, which may lead to masking of either of the illnesses or adverse implications on the course of illness and treatment outcomes. Some studies have found comorbidity to be as high as $90 \%$ in Adult ADHD. ${ }^{[22]}$
Common psychiatric comorbidities are depression, substance use disorders, generalized anxiety disorder, social phobia, specific phobia, panic disorder, bipolar disorder, dysthymia, obsessive-compulsive disorder, intermittent explosive disorder, and eating disorders. Among personality disorders, borderline, histrionic, narcissistic, and antisocial personality disorders are commonly comorbid. In the arena of medical comorbidities, hypertension, type II diabetes, obesity, asthma, and migraine are common. ${ }^{[8,19,23-37]}$ The presence of ADHD as a comorbid condition often adversely affects the course and outcome of these illnesses by way of early onset, increased severity, prolonged duration, increased complications, and chronicity or relapses. ${ }^{[38-42]}$ However, studies do suggest that timely appraisal and management of ADHD has affected the course and outcome of comorbid illness favorably ${ }^{[0]}$

4. Socio-occupational dysfunction: Presence of ADHD in an adult, with or without comorbidity, can lead to significant socio-occupational dysfunction. It has been seen that adults with ADHD have lower educational attainment, inability to gain or maintain employment, and lesser productivity owing to poor management of time, procrastination, distraction, or absenteeism. ${ }^{[43]}$ An adult with ADHD is at an increased risk of colliding, over-speeding, violating traffic rules, and risk-taking behavior while driving. ${ }^{[4,45]}$ When Adult ADHD is comorbid with substance use disorder or antisocial personality disorder, increased criminality or problems with the law have been noted $^{[46]}$

5. High heritability: ADHD in adults has been found to have high heritability ranging from $75 \%$ to $91 \% .{ }^{[8,47]}$ There is a $25.6 \%$ greater risk in parents, of children with $\mathrm{ADHD}$, and $20.8 \%$ greater risk in a sibling. ${ }^{[47]}$

\section{ADULT ATTENTION-DEFICIT HYPERACTIVITY DISORDER: THE CURRENT CONSTRUCT}

Studies have shown ADHD in adults to differ from ADHD in children, in some aspects. It has been observed that, with increasing age, inattentiveness tends to persist and has considerably lesser reduction than the hyperactivityimpulsivity symptom cluster. ${ }^{[2]}$ Inattention was clinically manifest as paying less attention to detail or being unable to manage time effectively. Hyperactivity was manifest as not being able to sit through meetings or frequent changes in jobs. Inattentiveness was seen as interrupting people, readiness to anger, and frequent job turnover. ${ }^{[46-50]}$ In addition, adults with ADHD have difficulty in modulating emotional responses, which may manifest as mood instability or liability. ${ }^{[8]}$ Many of these individuals choose an 
organized spouse, select work of less potential or rigorously structure their schedule to cope better. These may mask the diagnosis, thus highlighting the importance of eliciting these compensatory behaviors in psychosocial history. ${ }^{[48,51]}$

DSM V has modified the criteria to include older adolescents and adults in the ambit of ADHD, giving it a lifespan perspective. It has increased the age of onset from "before 7 years of age" to "before 12 years of age;" has lowered the required number of criteria from "6 out of 9" to "5 out of 9" for patients of age 17 and older; converted "evidence of impairment" to "evidence of symptoms in more than two settings;" and removed autistic spectrum disorder from the exclusion criteria. ${ }^{[4]}$

\section{ADULT-ONSET OR CHILDHOOD-ONSET ADULT ATTENTION-DEFICIT HYPERACTIVITY DISORDER: THE DEBATE}

Although most research finds a considerable amount of Childhood ADHD continuing to adulthood; there is some research which suggests the onset of $\mathrm{ADHD}$ in adults, without any evidence of its presence in childhood. Pelota's birth cohort study found that only $17 \%$ of childhood ADHD continued into adulthood and only $13 \%$ of young adults had onset of their ADHD in childhood. ${ }^{[52]}$ The New Zealand longitudinal cohort study indicated that $90 \%$ of adults with ADHD have no history of ADHD in their childhood and $85 \%$ of childhood ADHD did not extend into adulthood. The study contemplated the condition representing two almost nonoverlapping groups. ${ }^{[53]}$ E-risk longitudinal twin study found that two-third of ADHD patients diagnosed at 18 years of age did not have ADHD in their early childhood. Studies found adult-onset ADHD to have female preponderance, in comparison to equivocal preponderance in childhood-onset Adult ADHD. ${ }^{[54]}$ The current research has failed to reach a consensus on regarding this variability in presentation across the lifespan. Evidence-based research is likely to provide greater clarity in future.

\section{ASSESSMENT}

Both screening and diagnostic instruments are available for the assessment of Adult ADHD. As a large number of individuals with Adult ADHD remain undiagnosed, the need for screening and training of primary-care physicians in identification, early intervention, and timely referral to mental health professionals cannot be overemphasized.

Available screening and diagnostic instruments are as brought out in Table 1. ${ }^{[12,55-62]}$ More robust clinician-friendly tools, with higher specificity and validity, need to be scoped through a better understanding of the Adult ADHD

Table 1: Instruments of assessment of adult attention-deficit hyperactivity disorder

\begin{tabular}{|c|c|c|}
\hline Name of instruments & Type of instrument & Characteristics \\
\hline Kooij screening questions ${ }^{[55]}$ & Screening & 4 questions \\
\hline \multirow[t]{5}{*}{ ASRS $[56]$} & Screening & WHO compiled \\
\hline & & 18 items \\
\hline & & 6 item version available \\
\hline & & Specificity $96 \%$ \\
\hline & & Sensitivity $91.4 \%$ \\
\hline \multirow[t]{6}{*}{ WURS $[57]$} & Screening & 25 Items Scale \\
\hline & & Sensitivity $96 \%$ \\
\hline & & Specificity $96 \%$ \\
\hline & & Assesses ADHD and associated symptoms such as mood \\
\hline & & Provides retrospective account of childhood ADHD \\
\hline & & Often used in conjunction with ASRS \\
\hline \multirow[t]{3}{*}{ Conners Adult ADHD Rating Scale ${ }^{[58]}$} & Screening & Sensitivity $>90 \%$ \\
\hline & & Specificity $>90 \%$ \\
\hline & & Overall discriminant validity was $69 \%$ \\
\hline Adult ADHD Investigator Rating Scale $\mathrm{e}^{[59]}$ & Screening & 18 item semi structured interview \\
\hline \multirow[t]{2}{*}{ DIVA $2.0^{[60]}$} & Diagnostic & Sensitivity - 90\% \\
\hline & & Specificity - $83.3 \%$ \\
\hline \multirow[t]{2}{*}{$\mathrm{ACE}+{ }^{[61]}$} & Diagnostic & Semi structured interview \\
\hline & & Comprehensive interview for ADHD and co existing conditions \\
\hline \multirow[t]{2}{*}{ CAADID ${ }^{[62]}$} & Diagnostic & Structured interview \\
\hline & & Good reliability and validity \\
\hline Adult ADHD Clinical Diagnostic Scale ${ }^{[12]}$ & Diagnostic & Semi structured interview \\
\hline
\end{tabular}

ADHD - Attention deficit hyperactivity disorder; ASRS - ADHD Self-Report Scale; CAADID - Conners adult ADHD diagnostic interview of DSM IV; $A C E+-A D H D$ child evaluation+; WURS - Wender Utah Rating Scale; DIVA - Diagnostic instruments of adult ADHD 
construct across various phenomenological domains. False positivity in diagnosis remains a difficulty encountered by busy clinicians, which possibly leads to therapeutic nihilism from less than optimistic treatment outcomes.

\section{MANAGEMENT}

For the management of Adult ADHD, the major considerations which need to be addressed are the comorbidities, which are quite common. In addition, the treatment of ADHD has significant ramifications on the comorbid illness as well. ${ }^{[63]}$

Disorder-specific approach primarily includes pharmacological intervention. The commonly used medication groups are stimulants with which up to $75 \%$ immediate improvement has been noted. These medications are however avoided in patients with comorbid substance abuse or recent-onset tics or seizures. ${ }^{[64,65]}$ Nonstimulant medication takes longer for optimum effect. ${ }^{[64-66]}$ Various medication used for Adult ADHD is as brought out in Table 2.

Many nonpharmacological methods have been found useful. Recommended available methods are as per Table 3 .

\section{CONCLUSION}

Growing evidence from research has shown a large number of cases of ADHD among the adult population, which are comorbid with psychiatric illnesses, affecting their course and outcome. The phenomenology of Adult ADHD reflects greater attentional impairment than involvement of the hyperactivity-impulsive symptom cluster. Adult ADHD can significantly affect the quality of socio-occupational functioning. Better awareness of this entity, its timely identification and effective management, will significantly impact those suffering from Adult ADHD, as well as the

Table 2: Medications for adult attention-deficit hyperactivity disorder

\begin{tabular}{|c|c|c|}
\hline Medication & Types of formulations & Dosage \\
\hline \multicolumn{3}{|l|}{ Stimulants } \\
\hline \multirow[t]{4}{*}{ Methylphenidate } & Immediate release/short acting & $0.3-1.5 \mathrm{mg} / \mathrm{kg} / \mathrm{day}$ \\
\hline & Sustained release/intermediate acting & Maximum 108 mg/day \\
\hline & Extended release/long acting (pills/capsule) & \\
\hline & MPH patch & \\
\hline \multirow[t]{3}{*}{ Dextroamphetamine } & Immediate release & $0.3-1.5 \mathrm{mg} / \mathrm{kg}$ \\
\hline & Sustained release & Maximum $60 \mathrm{mg} / \mathrm{day}$ \\
\hline & Extended release (pills/capsules) & 20-6o mg/day \\
\hline \multicolumn{3}{|l|}{ Nonstimulants } \\
\hline \multirow[t]{2}{*}{ Atomoxetine } & Capsules & $0.5-1.2 \mathrm{mg} / \mathrm{kg} / \mathrm{day}$ \\
\hline & & Maximum $100 \mathrm{mg} / \mathrm{day}$ \\
\hline \multirow[t]{2}{*}{ Bupropion } & Plain and extended release tablets & $150-300 \mathrm{mg} / \mathrm{day}$ \\
\hline & & Maximum $450 \mathrm{mg} / \mathrm{day}$ \\
\hline \multirow[t]{2}{*}{ Desipramine } & Tablet & $1.5 \mathrm{mg} / \mathrm{kg} / \mathrm{day}$ \\
\hline & & Maximum $300 \mathrm{mg} / \mathrm{day}$ \\
\hline Clonidine & Plain and extended release tablets & $0.1-0.3 \mathrm{mg} / \mathrm{day}$ \\
\hline Guanfacine & Plain and extended release tablets & 1-7 mg/day \\
\hline Modafinil & Tablet & $200 \mathrm{mg} /$ day \\
\hline
\end{tabular}

ADHD - Attention deficit hyperactivity disorder; MPH - Methylphenidate

Table 3: Psychotherapy and other intervention in adult attention deficit hyperactivity disorder

\begin{tabular}{|c|c|}
\hline Intervention & Salient features \\
\hline Cognitive retraining ${ }^{[67]}$ & Effect size was larger for inattention and impulsivity domains than for hyperactivity \\
\hline Brain stimulation techniques ${ }^{[68]}$ & $\begin{array}{l}\text { Preliminary evidence is promising for transcranial magnetic stimulation and direct current } \\
\text { stimulation; but needs replication }\end{array}$ \\
\hline Psychotherapy ${ }^{[69,64]}$ & Cognitive behavior therapy has been found to be an useful adjunct to pharmacotherapy \\
\hline Yoga; meditation and mindfulness-based therapy ${ }^{[70]}$ & They have been found useful; but have not been replicated adequately \\
\hline Nature therapy ${ }^{[71]}$ & Green outdoor activities had more significantly reduction in symptoms than other settings \\
\hline Nutritional supplements ${ }^{[72]}$ & $\begin{array}{l}\text { Fish oil; zinc; iron; and magnesium and complex carbohydrates; can improve brain function and } \\
\text { reduce mood swings }\end{array}$ \\
\hline Exercise $^{[73]}$ & Improves executive functions \\
\hline ADHD coach ${ }^{[72]}$ & Addresses unique challenges with the condition and helps acquisition of skills to overcome these \\
\hline Neurobiofeedback ${ }^{[74]}$ & Being used in some setups with significant benefits. Reseach evidence inadequate \\
\hline
\end{tabular}

ADHD - Attention-deficit hyperactivity disorder 
comorbidities. The debate regarding childhood versus adult onset of Adult ADHD remains to be clarified through further research.

\section{Financial support and sponsorship}

Nil.

\section{Conflicts of interest}

There are no conflicts of interest.

\section{REFERENCES}

1. Mahadevan J, Kandasamy A, Benegal V. Situating adult attention-deficit/hyperactivity disorder in the externalizing spectrum: Etiological, diagnostic, and treatment considerations. Indian J Psychiatry 2019;61:3-12.

2. Spencer TJ, Biederman J, Mick E. Attention-deficit/ hyperactivity disorder: Diagnosis, lifespan, comorbidities, and neurobiology. J Pediatr Psychol 2007;32:631-42.

3. American Psychiatric Association. Diagnostic and Statistical Manual of Mental Disorders. $2^{\text {nd }}$ ed. Washington: American Psychiatric Publication; 1968.

4. American Psychiatric Association. Diagnostic and Statistical Manual of Mental Disorders (DSM- ${ }^{\circledR}$ ). Washington: American Psychiatric Publication; 2013.

5. American Psychiatric Association. Diagnostic and Statistical Manual of Mental Disorders: DSM-IV-TR. Washington, DC. American Psychiatric Publication; 2000.

6. Cherkasova M, Sulla EM, Dalena KL, Pondé MP, Hechtman L. Developmental course of attention deficit hyperactivity disorder and its predictors. J Can Acad Child Adolesc Psychiatry 2013;22:47-54.

7. Goodman DW. ADHD in Adults: Update for clinicians on diagnosis and assessment. Prim Psychiatry 2009;16:38.

8. Kessler RC, Adler L, Barkley R, Biederman J, Conners CK, Demler $\mathrm{O}$, et al. The prevalence and correlates of adult ADHD in the United States: Results from the national comorbidity survey replication. Am J Psychiatry 2006;163:716-23.

9. Ginsberg Y, Quintero J, Anand E, Casillas M, Upadhyaya HP. Underdiagnosis of attention-deficit/hyperactivity disorder in adult patients: A review of the literature. Prim Care Companion CNS Disord 2014;16:PCC.13r01600. doi: 10.4088/PCC.13r01600. Epub 2014 Jun 12. PMID: 25317367 ; PMCID: PMC4195639.

10. Fayyad J, De Graaf R, Kessler R, Alonso J, Angermeyer M, Demyttenaere K, et al. Cross-national prevalence and correlates of adult attention-deficit hyperactivity disorder. $\mathrm{Br}$ J Psychiatry 2007;190:402-9.

11. Das D, Cherbuin N, Easteal S, Anstey KJ. Attention Deficit/ hyperactivity disorder symptoms and cognitive abilities in the late-life cohort of the PATH through life study. PLoS One 2014;9:e86552.

12. Kessler RC, Green JG, Adler LA, Barkley RA, Chatterji S, Faraone SV, et al. Structure and diagnosis of adult attention-deficit/hyperactivity disorder: Analysis of expanded symptom criteria from the adult ADHD clinical diagnostic scale. Arch Gen Psychiatry 2010;67:1168-78.

13. Chung W, Jiang SF, Paksarian D, Nikolaidis A, Castellanos FX, Merikangas $\mathrm{KR}$, et al. Trends in the prevalence and incidence of attention-deficit/hyperactivity disorder among adults and children of different racial and ethnic groups. JAMA Netw Open 2019;2:e1914344.

14. de Graaf R, Kessler RC, Fayyad J, ten Have M, Alonso J, Angermeyer $\mathrm{M}$, et al. The prevalence and effects of adult attention-deficit/hyperactivity disorder (ADHD) on the performance of workers: Results from the WHO world mental health survey initiative. Occup Environ Med 2008;65:835-42.

15. Simon V, Czobor P, Bálint $S$, Mészáros A, Bitter I. Prevalence and correlates of adult attention-deficit/hyperactivity disorder: Meta-analysis. Br J Psychiatry 2009;194:204-11.

16. Simon V, Czobor P, Bálint S, Mészáros A, Murai Z, Bitter I. Detailed review of epidemiologic studies on adult attention-deficit/hyperactivity disorder (ADHD). Psychiatr Hung 2007;22:4-19.

17. Retz $W$, Retz-Junginger $P$, Thome J, Rösler M. Pharmacological treatment of adult ADHD in Europe. World J Biol Psychiatry 2011;12:89-94.

18. Newcorn JH, Weiss M, Stein MA. The complexity of ADHD: Diagnosis and treatment of the adult patient with comorbidities. CNS Spectr 2007;12:1-14.

19. Almeida Montes LG, Hernández García AO, Ricardo-Garcell J. ADHD prevalence in adult outpatients with nonpsychotic psychiatric illnesses. J Atten Disord 2007;11:150-6.

20. Nylander L, Holmqvist M, Gustafson L, Gillberg C. ADHD in adult psychiatry. Minimum rates and clinical presentation in general psychiatry outpatients. Nord J Psychiatry 2009;63:64-71.

21. Rao $P$, Place $M$. Prevalence of ADHD in four general adult outpatient clinics in North East England. Prog Neurol Psychiatry 2011;15:7-10.

22. Nutt DJ, Fone K, Asherson P, Bramble D, Hill P, Matthews K, et al. Evidence-based guidelines for management of attention-deficit/hyperactivity disorder in adolescents in transition to adult services and in adults: Recommendations from the British Association for Psychopharmacology. J Psychopharmacol 2007;21:10-41.

23. Davids E, Krause DA, Specka M, Gastpar M. Analysis of a special consultation for attention-deficit/hyperactivity disorder in adults. Gesundheitswesen 2004;66:416-22.

24. Cumyn L, French L, Hechtman L. Comorbidity in adults with attention-deficit hyperactivity disorder. Can J Psychiatry 2009;54:673-83.

25. Kooij JJ, Aeckerlin LP, Buitelaar JK. Functioning, comorbidity and treatment of 141 adults with attention-deficit/ hyperactivity disorder (ADHD) at a psychiatric outpatient department. Ned Tijdschr Geneeskd 2001;145:1498-501.

26. Cortese S, Ramos Olazagasti MA, Klein RG, Castellanos FX Proal E, Mannuzza S. Obesity in men with childhood ADHD: A 33-year controlled, prospective, follow-up study. Pediatrics 2013:131:e1731-8.

27. Katzman MA, Bilkey TS, Chokka PR, Fallu A, Klassen LJ. Adult ADHD and comorbid disorders: Clinical implications of a dimensional approach. BMC Psychiatry 2017;17:302.

28. Chen Q, Hartman CA, Haavik J, Harro J, Klungsøyr K, Hegvik TA, et al. Common psychiatric and metabolic comorbidity of adult attention-deficit/hyperactivity disorder: A population-based cross-sectional study. PLoS One 2018;13:e0204516.

29. Sobanski E. Psychiatric comorbidity in adults with attention-deficit/hyperactivity disorder (ADHD). Eur Arch Psychiatry Clin Neurosci 2006;256:i26-31.

30. Asherson P, Akehurst R, Kooij JJ, Huss M, Beusterien K, Sasané $\mathrm{R}$, et al. Under diagnosis of adult ADHD: Cultural influences and societal burden. J Atten Disord 2012;16:20S-38S.

31. Pagoto SL, Curtin C, Bandini LG, Anderson SE, Schneider KL, Bodenlos JS, et al. Weight loss following a clinic-based weight loss program among adults with attention deficit/ hyperactivity disorder symptoms. Eat Weight Disord 2010;15:e166-72.

32. Levy LD, Fleming JP, Klar D. Treatment of refractory obesity in severely obese adults following management of newly diagnosed attention-deficit/hyperactivity disorder. Int J Obes (Lond) 2009;33:326-34.

33. Fasmer OB, Halmøy A, Oedegaard KJ, Haavik J. Adult attention-deficit/hyperactivity disorder is associated with 
migraine headaches. Eur Arch Psychiatry Clin Neurosci 2011;261:595-602.

34. Wasserstein J. Diagnostic issues for adolescents and adults with ADHD. J Clin Psychol 2005;61:535-47.

35. Matthies S, Philipsen A. Comorbidity of personality disorders and adult attention deficit hyperactivity disorder (ADHD) Review of recent findings. Curr Psychiatry Rep 2016;18:33.

36. Ferrer $M$, Andión O, Matalí J, Valero S, Navarro JA, Ramos-Quiroga JA, et al. Comorbid attention-deficit/ hyperactivity disorder in borderline patients defines an impulsive subtype of borderline personality disorder. J Pers Disord 2010;24:812-22.

37. Geller DA. Obsessive-compulsive and spectrum disorders in children and adolescents. Psychiatr Clin North Am 2006;29:353-70.

38. Nierenberg AA, Miyahara S, Spencer T, Wisniewski SR, Otto MW, Simon N, et al. Clinical and diagnostic implications of lifetime attention-deficit/hyperactivity disorder comorbidity in adults with bipolar disorder: Data from the first 1000 STEP-BD participants. Biol Psychiatry 2005;57:1467-73.

39. Harmanci $H$, C Cam Celikel F, Etikan I. Comorbidity of adult attention deficit and hyperactivity disorder in bipolar and unipolar patients. Noro Psikiyatr Ars 2016;53:257-62.

40. Marsh PJ, Williams LM. ADHD and schizophrenia phenomenology: Visual scanpaths to emotional faces as a potential psychophysiological marker? Neurosci Biobehav Rev 2006;30:651-65.

41. Murray MJ. Attention-deficit/Hyperactivity Disorder in the context of Autism spectrum disorders. Curr Psychiatry Rep 2010;12:382-8.

42. Schatz DB, Rostain AL. ADHD with comorbid anxiety: A review of the current literature. J Atten Disord 2006;10:141-9.

43. Secnik K, Swensen A, Lage MJ. Comorbidities and costs of adult patients diagnosed with attention-deficit/hyperactivity disorder. Pharmacoeconomics 2005;23:93-102.

44. Cox DJ, Madaan V, Cox BS. Adult attention-deficit/ hyperactivity disorder and driving: Why and how to manage it. Curr Psychiatry Rep 2011;13:345-50.

45. Fried R, Petty CR, Surman CB, Reimer B, Aleardi $M$, Martin JM, et al. Characterizing impaired driving in adults with attention-deficit/hyperactivity disorder: A controlled study. J Clin Psychiatry 2006;67:567-74.

46. Mariani JJ, Levin FR. Treatment strategies for co-occurring ADHD and substance use disorders. Am $J$ Addict 2007; 16:45-54.

47. Culpepper L, Mattingly G. Challenges in identifying and managing attention-deficit/hyperactivity disorder in adults in the primary care setting: A review of the literature. Prim Care Companion J Clin Psychiatry 2010;12:PCC.10r00951.

48. Adler L, Cohen J. Diagnosis and evaluation of adults with attention-deficit/hyperactivity disorder. Psychiatr Clin North Am 2004;27:187-201.

49. Montano B. Diagnosis and treatment of ADHD in adults in primary care. J Clin Psychiatry 2004;65:18-21.

50. Kessler RC, Adler L, Ames M, Demler O, Faraone S, Hiripi E, et al. The world health organization adult ADHD self-report scale (ASRS): A short screening scale for use in the general population. Psychol Med 2005;35:245-56.

51. Weiss MD, Weiss JR. A guide to the treatment of adults with ADHD. J Clin Psychiatry 2004;65:27-37.

52. Caye A, Rocha TB, Anselmi L, Murray J, Menezes AM, Barros FC, et al. Attention-deficit/hyperactivity disorder trajectories from childhood to young adulthood: Evidence from a birth cohort supporting a late-onset syndrome. JAMA Psychiatry 2016;73:705-12.

53. Moffitt TE, Houts R, Asherson P, Belsky DW, Corcoran DL, Hammerle $\mathrm{M}$, et al. Is adult ADHD a childhood-onset neurodevelopmental disorder? Evidence from a four-decade longitudinal cohort study. Am J Psychiatry 2015;172:967-77.

54. Agnew-Blais JC, Polanczyk GV, Danese A, Wertz J, Moffitt TE,
Arseneault L. Evaluation of the persistence, remission, and emergence of attention-deficit/hyperactivity disorder in young adulthood. JAMA Psychiatry 2016;73:713-20.

55. Kooij JJ. Adult ADHD: Diagnostic Assessment and Treatment. $3^{\text {rd }}$ ed. Amsterdam, the Netherlands: Pearson Assessment and Information; 2013. p. 34.

56. Ustun B, Adler LA, Rudin C, Faraone SV, Spencer TJ, Berglund $\mathrm{P}$, et al. The World Health Organization adult attention-deficit/hyperactivity disorder self-report screening scale for DSM-5. JAMA Psychiatry 2017;74:520-7.

57. Hill BD, Pella RD, Singh AN, Jones GN, Gouvier WD. The Wender Utah rating scale: Adult ADHD diagnostic tool or personality index? J Atten Disord 2009;13:87-94.

58. Taylor A, Deb S, Unwin G. Scales for the identification of adults with attention deficit hyperactivity disorder (ADHD): A systematic review. Res Dev Disabil 2011;32:924-38.

59. Spencer TJ, Adler LA, Qiao M, Saylor KE, Brown TE, Holdnack JA, et al. Validation of the adult ADHD investigator symptom rating scale (AISRS). J Atten Disord 2010;14:57-68.

60. Kooij JJ, Francken MH. Diagnostic Interview for ADHD in Adults 2.0 (DIVA 2.0). Adult ADHD Diagnostic Assessment and Treatment. The Netherlands: Pearson Assessment and Information BV; 2010.

61. Young S. Diagnostic Interview of ADHD in Adults; 2016. Available from: https://www.psychology-services.uk.com /adhd.htm. [Last accessed on 2020 Dec 21].

62. Epstein JN, Kollins SH. Psychometric properties of an adult ADHD diagnostic interview. J Atten Disord 2006;9:504-14.

63. Kooij JJ, Bijlenga D, Salerno L, Jaeschke R, Bitter I, Balázs J, et al. Updated European consensus statement on diagnosis and treatment of adult ADHD. Eur Psychiatry 2019;56:14-34.

64. Volkow ND, Swanson JM. Clinical practice: Adult attention deficit-hyperactivity disorder. N Engl J Med 2013;369:1935-44.

65. Kolar D, Keller A, Golfinopoulos M, Cumyn L, Syer C, Hechtman L. Treatment of adults with attention-deficit/ hyperactivity disorder. Neuropsychiatr Dis Treat 2008;4:389-403.

66. Ravishankar V, Chowdappa SV, Benegal V, Muralidharan K. The efficacy of atomoxetine in treating adult attention deficit hyperactivity disorder (ADHD): A meta-analysis of controlled trials. Asian J Psychiatr 2016;24:53-8.

67. Arns M, de Ridder S, Strehl U, Breteler M, Coenen A. Efficacy of neurofeedback treatment in ADHD: The effects on inattention, impulsivity and hyperactivity: A meta-analysis. Clin EEG Neurosci 2009;40:180-9.

68. Brandejsky L, Micoulaud Franchi JA, Lopez R, Bioulac S, Da Fonseca D, Daudet C, et al. Noninvasive cerebral stimulation for treatment of ADHD: A review of the literature. Encephale 2017;43:457-63.

69. Young Z, Moghaddam N, Tickle A. The efficacy of cognitive behavioral therapy for adults with ADHD: A systematic review and meta-analysis of randomized controlled trials. J Atten Disord 2020;24:875-88.

70. Chimiklis AL, Dahl V, Spears AP, Goss K, Fogarty K, Chacko A. Yoga, mindfulness, and meditation interventions for youth with ADHD: Systematic review and meta-analysis. Child Fam Stud 2018;27:3155-68.

71. Kuo FE, Taylor AF. A potential natural treatment for attention-deficit/hyperactivity disorder: Evidence from a national study. Am J Public Health 2004;94:1580-6.

72. William P. Adult ADHD Treatment Options - An Overview. Available from: https://www.additudemag.com/ adhd-treatment-options-adult. [Last accessed on 2021 Jan 08; Last updated on 2020 Feb 28].

73. Ratey JJ, Hageman E. Spark: The Revolutionary New Science of the Exercise and Brain Complex. New York: Little, Brown and Company; 2013.

74. Guan Lim C, Lim-Ashworth NSJ, Fung DSS. Updates in technology-based interventions for attention deficit hyperactivity disorder. Curr Opin Psychiatry 2020;33:577-85. 